\title{
CONTRATO E CONFEDERAÇÃO. NOTAS SOBRE O PAPEL DAS RELACCÕES INTERNACIONAIS NO PENSAMENTO POLÍTICO DE JEAN-JACQUES ROUSSEAU ${ }^{1}$
}

\author{
J osé Oscar de AImeida MARQUES
}

\begin{abstract}
RE SU M O: A o ler o Contrato social de Rousseau, tendemos a nos concentrar em seu objetivo explícito, que é o de investigar e estabelecer uma regra de administração legítima e segura para uma comunidade política individual. Em conformidade com o próprio caráter abstrato da obra, somos levados a ver essa comunidade como alguma coisa pré-existente e isolada, sem perguntar o que já havia inicialmente de comum a esses indivíduos que decidem submeter-se à regra de sua vontade geral, e como esse corpo político assim constituído se relaciona com os que não são eles mesmos, mas "os outros", isto é, com as demais sociedades com as quais terá inevitavelmente de conviver. Tais questões tinham grande importância para Rousseau, e só o caráter fragmentário e inconcluso do Contrato social explica por que não receberam o tratamento aprofundado que Ihes seria devido. Pretendo, em minha exposição, explorar alguns aspectos das soluções que Rousseau deixou esboçadas em outras obras, especialmente no Emílio e em seu Extrato e J ulgamento, do projeto de paz perpétua do A bbé de Saint-Pierre, e que apontam para uma compreensão muito lúcida do problema das relações entre as nações, e para uma solução que tem, surpreendentemente, muito em comum com a que propôs, no Contrato social, para a questão das relações entre indivíduos. Pretendo mostrar que há, em Rousseau, o gérmen de uma concepção das relações internacionais que não as reduz ao mero jogo de forças proposto pelo "realismo" hobbesiano e, ao mesmo tempo, viabiliza a convivência civilizada e regulada, sem impor a uniformidade de valores e perspectivas característica do cosmopolitismo kantiano.
\end{abstract}

PALAVRA S-CHA VE: Relações internacionais. Rousseau. Filosofia política.

'Uma versão preliminar deste texto, intitulada "Rousseau e as relações internacionais", foi apresentada no III Colóquio Rousseau, realizado na Universidade Federal da Bahia, em Salvador, de 29 a 31 de agosto de 2007.

* Departamento de Filosofia - IFCH - Unicamp. 
O Contrato social é um torso. Vemos isso ao compará-lo com as obras políticas de Platão e A ristóteles, muito mais detalhadas em seu exame de aspectos concretos da vida social, como a economia, a organização familiar, a educação, a música e as artes.

Não sabemos se, caso Rousseau tivesse concluído a obra inicialmente planejada (as Instituições políticas), encontraríamos ali um detalhamento comparável desses assuntos internos à comunidade política. Sabemos, porém, pela leitura do último parágrafo do Contrato social, que Rousseau pretendia examinar diversos aspectos ligados às relações externas entre os Estados: 0 direito das gentes, o comércio, o direito da guerra e das conquistas, as ligas, as associações e os tratados. ${ }^{2}$ A lgumas indicações mais precisas da importância que Rousseau atribuía a esse exame estão dadas no Livro V do Emílio, em que se oferece um resumo do Contrato social que avança além do ponto em que a obra publicada se deteve. Essas indicações deixam claro que, para o autor, o tema das relações externas não era uma mera complementação à discussão já efetuada, mas que esses dois domínios, interno e externo, se interpenetram e trazem profundas implicações um para o outro. A passagem merece ser citada na íntegra:

A pós termos assim considerado cada espécie de sociedade civil nela mesma, nós as compararemos para observar suas diversas relações: umas grandes, outras pequenas; umas fortes, outras fracas; atacando-se, ofendendo-se e destruindo-se uma às outras; e, nessa contínua ação e reação, fazendo mais miseráveis e custando mais vidas humanas do que ocorreria se todos os homens tivessem mantido sua liberdade inicial. Examinaremos se não se fez demasiado, ou demasiado pouco na instituição social; se os indivíduos submetidos às leis e aos homens, enquanto as sociedades guardam entre si a independência natural, não ficam mais expostos aos males das duas condições sem ter a vantagem de nenhuma; e se não seria melhor não haver nenhuma sociedade civil no mundo do que a existência de tantas delas. Não é exatamente essa condição mista, que participa das duas e não assegura nenhuma, per quem neutrum licet, nec tanquam in bello paratum esse, nec tanquam in pace securum $?^{3}$ Não é essa associação parcial e imperfeita que produz a tirania e a guerra, e não são estas os dois maiores flagelos da humanidade?

Examinaremos, por fim, como se buscou remediar esses inconvenientes por meio das ligas e confederações que, deixando cada Estado senhor de si internamente, armam-no por fora contra todo agressor injusto. Procuraremos

\footnotetext{
${ }^{2}$ ROUSSEAU, J J . Du contrat social, Livro IV, seção ix. In: Oeuvres complètes, v. III, p. 470, doravante, para simplificar, OC iii 470.

3 "que não permite nem estar preparado em tempo de guerra nem seguro em tempo de paz", (Sêneca, Da tranqüilidade da alma, cap. I).
} 
como se pode estabelecer uma boa associação federativa, o que pode tornála durável, e até que ponto se pode estender o direito da confederação sem prejudicar o da soberania.

O Abbé de Saint-Pierre havia proposto uma associação de todos os Estados da Europa para manter entre eles uma paz perpétua. Mas seria viável essa associação, e, supondo-se que tivesse sido estabelecida, é de supor que teria durado? Essas investigações levam-nos diretamente a todas as questões do direito público que podem terminar de esclarecer aquelas do direito político. ${ }^{4}$

Essas observações de Rousseau esclarecem que, para ele, o Contrato social, na forma em que foi finalmente publicado, acha-se ainda a meiocaminho na tarefa de estabelecer uma sociedade civil capaz de preservar a liberdade e garantir a segurança de seus membros. 0 que se fez, ao se retirar a independência natural dos homens e submetê-los às leis e aos outros homens, foi talvez "demasiado"; ou então, "demasiado pouco", ao se permitir que as sociedades continuassem preservando sua liberdade natural umas em relação às outras. 0 resultado é uma condição mista que alia submissão interna e insegurança externa, fazendo com que os homens, que no estado natural de independência teriam a temer apenas o poder de outros homens isolados, defrontem-se agora com a formidável ameaça do poder bélico próprio das sociedades organizadas. Um círculo vicioso se instaura: a insegurança externa serve de justificativa para a centralização e ampliação do governo e para as medidas coercitivas de captação de recursos e convocação militar. E, à medida que os príncipes se fortalecem dessa forma, seu interesse particular separa-se do da população em geral e os estimula às aventuras de conquista. Eis por que Rousseau pode afirmar que tanto a tirania como a guerra são os resultados desastrosos desse modo de associação imperfeita que estabiliza internamente os Estados, deixando-os desimpedidos em sua ação externa.

Parece claro, portanto, o que falta realizar: é preciso estender a obra do Contrato social e realizar para as comunidades aquilo que se havia feito para os indivíduos, a saber, sua "desnaturalização", ou saída do Estado de Natureza, de modo a libertar os homens dos flagelos da guerra externa e da tirania interna, assegurando-Ihes, ao mesmo tempo, a liberdade civil e a segurança.

Esse objetivo tem uma importância extrema para um Estado com as características daquele descrito no Contrato social, isto é, um Estado

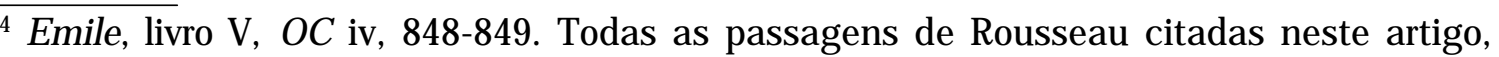
foram traduzidas por mim.
} 
pequeno, que é o único que, para Rousseau, merece ser preservado. ${ }^{5}$ Isso mostra, assim, que o problema das relações internacionais não é, para Rousseau, uma área separada que constituiria uma disciplina específica e independente da discussão da constituição política interna de um Estado. Há uma relação crucial entre esses dois âmbitos; e o plano geral do Contrato Social exige, para completar-se, o equacionamento do problema das relações externas.

\section{II}

O próximo passo, por conseguinte, se Rousseau tivesse estendido a redação do Contrato social nos moldes acima apresentados, deveria ser um exame da forma pela qual se pretende alcançar esse objetivo, por meio dos mecanismos das ligas e confederações, e avaliar em que medida essa solução é factível e compatível com a preservação da soberania dos Estados e da autonomia dos cidadãos. Rousseau também indica que tomaria como ponto de partida uma obra que ele havia estudado em profundidade, o Projeto para a paz perpétua do A bbé de Saint-Pierre, da qual havia feito um resumo e um estudo crítico. ${ }^{6}$ De fato, o diagnóstico da situação havia sido claramente produzido por Saint-Pierre: a instabilidade nas relações entre os países europeus decorre de não haver garantia de cumprimento de acordos internacionais que pudessem garantir a paz. Ao agirem cada qual segundo seus interesses particulares mais ou menos imediatos, as potências soberanas se colocam na situação de guerra de todos contra todos, famosamente descrita por Hobbes.

Como se sabe, Hobbes conseguira solucionar esse problema para 0 caso das comunidades de indivíduos, pela instituição do poder civil capaz de impor as regras de convivência pacífica, mas não julgava que a mesma solução fosse aplicável ao caso das potências, pela impossibilidade de erigir,

\footnotetext{
${ }^{5}$ Como nota Vaughan: "the small State has more to fear from unjust aggression than the large; that tyranny, which is the natural destiny of the large State, is contrary to the whole end and being of the small. For this reason, Federation is, in a special sense, the interest of the small State rather than the large. It is the weapon with which both reason and experience teach the small State to arm itself against the greed and insolence of the large. That is the reason why Federation lay so close to the heart of Rousseau. In his view-and who shall gainsay him? - it is the only means of preserving the small State, which to him is the only State w orth having, from being swept, as in a tempest, off the face of the earth" (ROUSSEAU, J.-J . The political writings of J ean J acques Rousseau, 1915, v.1, p. 72).

${ }^{6}$ Rousseau. Extrait du Projet de Paix Perpétuelle de Monsieur l'Abbé de Saint Pierre e J ugement sur le Projet de Paix Perpétuelle, OC iii 563-616.
} 
acima de todas elas, um poder coercitivo suficientemente forte para mantêlas todas sob controle. De qualquer maneira, a solução de Hobbes apoiavase na cessão voluntária da liberdade original em troca da segurança garantida por um poder irresistível acima dos contratantes, o que, se transposto para 0 campo das relações internacionais, implicaria a criação de um governo mundial e a eliminação de toda soberania dos povos e nações - uma solução, é claro, completamente inaceitável para Rousseau.

No Contrato social, Rousseau buscou resolver a questão de como alcançar a paz e estabilidade internas de uma comunidade sem apelar para o despotismo hobbesiano, fornecendo uma garantia contra as agressões e assegurando o respeito à vida e à propriedade, ao mesmo tempo em que preservava a liberdade política dos indivíduos. Para Rousseau, e ao contrário do que propunha Hobbes, o objetivo da vida em comunidade não é apenas atender aos interesses de sobrevivência e de uma vida confortável, mas é antes moral, ligado ao exercício autônomo da liberdade, fazendo com que a obediência à lei seja a obediência à expressão da vontade geral. Essa é a solução de Rousseau para o problema da política.

No entanto, como se argumentou acima, essa solução é incompleta e incapaz, por si só, de assegurar a preservação da comunidade política diante da ameaça latente das demais sociedades independentes em meio às quais terá de viver. Mas, como transpor a solução do problema da convivência para a esfera internacional? Como criar essa confederação de Estados soberanos capaz de preservar a soberania de seus membros e, ao mesmo tempo, impor-Ihes uma regra, de modo a assegurar a paz e o respeito mútuo entre os Estados?

Colocado nesses termos, o problema apresenta-se como muito semelhante àquele resolvido pelo Contrato social. Um exame da discussão que Rousseau realizou sobre o trabalho de Saint-Pierre permitirá realçar essa proximidade. Como o próprio Rousseau indica, no final da passagem citada acima, há dois pontos a serem considerados nesse exame: em primeiro lugar, entender qual é, exatamente, a proposta de Saint-Pierre para alcançar a paz e a cooperação entre as potências soberanas, e, em segundo lugar, examinar a viabilidade prática de implementar essa solução. Trataremos dessas questões separadamente.

III

A ideia central de Saint-Pierre é estabelecer uma confederação entre os Estados, na qual todos os membros tenham igual estatuto e nenhum possa impor sua vontade a outros. Assim como os indivíduos do Contrato 
social, os membros da confederação devem ser livres e iguais. Como, entre as nações, essa igualdade em força e poder dificilmente ocorre, é preciso cuidar de garanti-la, contrapondo cada Estado ao poder conjugado dos demais, de tal sorte que nenhum seja suficientemente forte para enfrentar a todos os outros reunidos. Feito isso, impõe-se a igualdade em termos de direitos e obrigações, válidos para todos de forma geral, sem tolerar qualquer prerrogativa particular. Esses pontos são assinalados por Rousseau, no Extrato, em que resume o projeto de Saint-Pierre:

Para formar um confederação sólida e durável, é preciso colocar todos os seus membros em uma dependência de tal modo mútua que nenhum esteja, sozinho, em condições de resistir a todos os outros, e que as associações particulares que poderiam prejudicar a grande encontrem aí obstáculos suficientes para impedir sua execução, sem o que a confederação seria vã e cada qual seria de fato independente, sob uma aparente sujeição. anterior:

Ainda mais reveladora é a seguinte passagem do Extrato, um pouco

Se há algum meio de resolver essas perigosas contradições, só pode ser por uma forma de governo confederativo que, unindo os povos por liames semelhantes aos que unem os indivíduos, submete igualmente uns e outros à autoridade das Leis.

0 que é importante notar aqui é que essa submissão às leis, embora garantida pela força, não tem seu fundamento na força. Esse é um ponto crucial, como sabemos pela leitura do Contrato social. Se os Estados vão preservar sua soberania, como indicado acima, eles devem preservar sua liberdade, e a forma de obter isso, analogamente à solução proposta no Contrato social, é identificar a obediência à lei como obediência à vontade geral. De forma implícita, parece que essas passagens representam algo como uma transposição da obediência à vontade geral para o domínio dos Estados independentes.

Ora, todas as ideias apresentadas nessas passagens do Extrato representam, supostamente, as propostas do próprio Saint-Pierre, e estão sendo apenas resumidas por Rousseau. ${ }^{9}$ M as é notável como elas ecoam, ou

\footnotetext{
${ }^{7}$ OC iii, 573.

${ }^{9}$ OC iii, 564, grifo nosso.
}

${ }^{9}$ Isso, entretanto, só poderá ser estabelecido conclusivamente por meio de uma leitura dos escritos originais do Abbé, o que não realizei até o momento. É preciso, de fato ter em mente as palavras de Rousseau, nas Confissões: "De resto, não me limitando à função de tradutor, não me era proibido pensar ocasionalmente por mim mesmo, e eu podia dar à minha obra uma forma tal que importantes verdades ali passariam sob o manto do Abbé de St. Pierre com maior felicidade do que sob o meu" (OC i 408). 
talvez, mais propriamente, antecipem, as teses do Contrato social. E, de fato, não é implausível supor, como faz Yuichi Aiko, ${ }^{10}$ que o acordo dos dois autores nesses tópicos essenciais resulta de uma influência direta do trabalho de Saint-Pierre na elaboração da doutrina que Rousseau apresentou no Contrato social.

Algumas considerações cronológicas permitem dar algum peso a essa conjetura. A pós a publicação do Primeiro Discurso, em 1750, Rousseau, na esteira da série de respostas às objeções suscitadas por seu livro, começa a elaborar as ideias para suas Instituições políticas. Em 1754, ele concluiu 0 Segundo Discurso, mas nessa obra ele ainda concebia o estabelecimento do corpo político como um contrato entre o povo e os chefes que este escolheu; 11 assim, ainda não está presente a ideia fundamental do Contrato social. É só na Economia Política, publicada em novembro de 1755, que, pela primeira vez, a noção de "vontade geral" é anunciada:

Que a vontade geral consinta que um membro do Estado, quem quer que seja, fira ou destrua um outro, não é mais inacreditável do que consentir que os dedos de um homem no uso da razão arranquem seus olhos. A segurança particular está de tal modo ligada à confederação pública que [...] essa convenção seria destruída por direito se perecesse no Estado um só que se tivesse podido socorrer, se um só fosse mantido erroneamente na prisão, e se se perdesse um só processo por uma injustiça evidente. Pois se as convenções fundamentais estão afrontadas não se vê mais que direito ou que interesse poderiam manter o povo numa união social, a não ser pela pura força, o que traz a dissolução do estado civil.

É plausível afirmar que a Economia Política tenha sido redigida após o retorno de Rousseau de Genebra, em 1754, exatamente na época em que começou a ocupar-se dos trabalhos de Saint-Pierre e, nesse caso, poderia não ser acidental o uso, por Rousseau, da palavra "confederação" (que é o termo que ele emprega em seu Extrato, para designar a união dos Estados), a fim de indicar, aqui, a união dos indivíduos na sociedade.

Também no Manuscrito de Genebra Rousseau empregou a palavra "confederação", em uma passagem absolutamente crucial, que contém a definição do contrato:

0 ato da confederação primitiva inclui um compromisso recíproco do público com indivíduos e cada indivíduo contratando como que consigo mesmo,

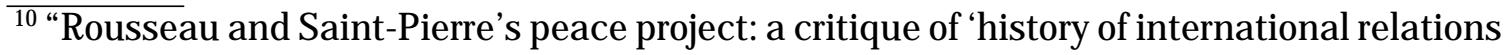
theory'".

${ }^{11}$ OC iii 184.

${ }^{12}$ OC iii 256.
} 
encontra-se em relações duplas, a saber, como membro do Soberano frente a cada indivíduo, e como membro do Estado frente ao Soberano. ${ }^{13}$

O que pode ter servido de inspiração a Rousseau é exatamente a posição intransigente de Saint-Pierre quanto à natureza moral das obrigações internacionais, que só pode ser alcançada se cada Estado atuar livremente de acordo com a regra estabelecida por seus contratos. A qui, a noção de soberania não significa agir da forma que se quiser, arbitrariamente e sem qualquer restrição; ao contrário, a verdadeira independência e liberdade consistem em estar em condições reais de usufruir seus direitos (de forma semelhante à discussão da liberdade individual, no Contrato social), o que exige a ação seja moralmente respaldada. Esse ponto parece estar claramente apresentado em Saint-Pierre, e Rousseau parece estar em plena concordância com essa proposta. Ingressar em uma confederação é uma maneira de aumentar a soberania, não de diminuí-la, pois a alegada independência absoluta dos soberanos só Ihes traz realmente riscos e insegurança. Obedecer à "vontade geral", tanto para os Estados como para os indivíduos, não é abdicar de seus legítimos interesses em prol de uma coletividade impessoal ou supranacional, mas é exatamente atender do modo mais efetivo esses mesmos interesses, conciliando a liberdade e o cumprimento à regra que se escolheu.

\section{IV}

É comum dizer-se que Rousseau rejeitou o projeto de paz perpétua formulado por Saint-Pierre, mas essa é uma simplificação que precisa ser corrigida. Rousseau manifestou sua admiração e concordância com os objetivos de Saint-Pierre, e certamente viu a confederação como a forma de alcançáIos, 0 que ele não aceitou é que o projeto pudesse ser efetivamente implementado no contexto europeu, dada a própria natureza dos sistemas de governo monárquicos absolutistas, que são refratários a considerações ligadas a seu próprio bem-estar e interesse. Do mesmo modo que a violência, a destruição e a frieza são muito maiores nas guerras entre Estados do que nas lutas entre indivíduos, também a loucura e insanidade se manifestam muito mais na ação dos soberanos ávidos de conquistas e dominação que em indivíduos isolados, os quais, mais frágeis, tendem a agir mais prudentemente. Príncipes não estão realmente interessados na paz, mas em aumentar seus ganhos e sua margem de movimento e dominação interna, contando com a instabilidade externa para favorecê-los na busca desses objetivos.

\footnotetext{
${ }^{13}$ OC iii 290.
} 
Assim, para Rousseau, sem uma reforma das próprias formas internas de governo e a substituição dos absolutismos pelas repúblicas, não haveria nenhuma perspectiva de alterar o belicoso e instável cenário internacional europeu. Para tanto, seria preciso que os monarcas fossem, conforme 0 modelo do Contrato social, apenas os administradores e executores das decisões oriundas da vontade geral, que é a única capaz de definir corretamente os reais interesses de um Estado. 0 erro de Saint-Pierre, segundo Rousseau, foi ter ingenuamente suposto que os príncipes europeus estariam em condições de discernir o real interesse das comunidades que governam e, ainda que o fizessem, adotar esse interesse superando sua cobiça pessoal, que os leva necessariamente a buscar o confronto internacional. A confederação, para ser estabelecida externamente, tem como pré-condição a reforma interna prévia das sociedades que dela participarão.

É preciso notar, por fim, que o pessimismo de Rousseau não o torna um "realista", em termos da teoria das Relações Internacionais, como muitas vezes se propõe. ${ }^{14}$ Rousseau não entende que a soberania das nações deva expressar-se como a independência absoluta e o direito ilimitado a todas as coisas, característicos do Estado de natureza hobbesiano. Em sua severa crítica do projeto de Saint-Pierre. Rousseau não contestou a justeza do objetivo do Abbé (a paz perpétua), nem a correção dos meios que este propôs para alcançá-la (o estabelecimento da Confederação), mas apenas insistiu sobre sua impraticabilidade contingencial, no contexto europeu da época.

V

A título de palavras finais, deixo algumas questões sobre se mesmo os Estados perfeitamente constituídos segundo o modelo do Contrato social poderiam, afinal, conviver estavelmente nessa confederação de Estados. Sem dúvida, o quadro conceitual de Rousseau introduz várias dificuldades para essa convivência e, de fato, em suas obras mais "práticas", as receitas que Rousseau propõe são o isolamento e a busca de autossuficiência, o que revela sua descrença quanto à possibilidade de estabelecer acordos internacionais sólidos e confiáveis, particularmente quando envolvem parceiros muito diferentes quanto ao poder militar e econômico de que dispõem.

$E$, de fato, a hipótese de que governos republicanos seriam intrinsecamente mais voltados para a paz não encontra confirmação histórica, já que bastam os exemplos de A tenas e da república romana para refutá-la. A

${ }^{14}$ Cf. Fonseca J r., 2003, p. xii. 
vontade geral é geral para uma dada comunidade, mas é particular diante de outras comunidades, e as repúblicas, por sua coesão e entusiasmo cívico, são até mais capazes de impor com frieza e efetividade sua vontade às demais.

Por outro lado, Rousseau não aceita que o ingresso em uma era de progresso técnico e intercâmbio comercial pudesse por si só conduzir à estabilidade e cooperação internacionais; ao contrário, ele julga que, com isso, se introduzem, antes, maiores fatores de desagregação e desequilíbrio nas relações internacionais, pela disputa de recursos e mercados. Nesse sentido, ele se afasta do otimismo dos pensadores do lluminismo, em sua vertente liberal.

Há, além disso, fatores profundos que atuam na consolidação do corpo político do Contrato social e que simplesmente não encontram equivalente, no âmbito da sociedade de nações. Entre eles, a religião civil patriótica e o sentimento comunitário excludente que fortalece os liames internos. Assim, o avanço do cosmopolitismo, que Kant via como o caminho que levaria finalmente à paz perpétua, não é uma resposta viável para Rousseau, na medida em que enfraquece o sentido de coesão nacional e destrói, em seu caminho, as pequenas comunidades com seus valores próprios e específicos, e que são a expressão do que haveria a preservar na aventura da socialização. De fato, a paz alcançada por meio da eliminação das diferenças e dos caracteres nacionais, e pela completa homogeneização dos valores e culturas, seria a paz dos "últimos homens", e não mais desejável que a paz dos cemitérios.

MARQUES, J osé Oscar de AImeida. Contract and confederation. Notes on the role of international relations in J ean-J acques Rousseau's political thought. Trans/Form/Ação, (São Paulo); v.33(1), 2010, p.19-30.

\footnotetext{
A BSTRA CT: When we read Rousseau's Social Contract, we tend to focus on its explicit goal, which is to investigate and establish a safe and legitimate rule of administration for a single political community. In accordance with the abstract character of the work, we tend to see this community as something pre-existing and isolated, without asking what those individuals who decide to submit to the rule of his general will had initially in common, and how the political body thus formed is related to those who are not they themselves, but "the others", i.e., with other societies among which they will inevitably have to live. Such issues were of great importance to Rousseau, and only the fragmentary and inconclusive nature of the Social Contract explains why they did not receive the detailed treatment that would be due to them. In this paper I intend to explore some aspects of the solutions Rousseau left sketched elsewhere, especially in Emile and in the Extract and J udgment of the the Abbé de Saint-Pierre's project of perpetual peace, which point to Rousseau's very lucid understanding of the problem of relations between nations, and to a solution that has, surprisingly, much in common with the one that he proposed, in the Social Contract, to the problem of relations between individuals. I Intend to show that there is, in Rousseau, the germ of a conception of international relations that do
} 
not reduce them to the mere play of forces proposed by Hobbesian "realism" and, at the same time, allows a regulated and civilized coexistence without imposing the uniformity of values and perspectives characteristic of Kantian cosmopolitanism.

KEYWORDS: International Relations. Rousseau. Political Philosophy.

\section{Referências}

AIKO, Yuichi. Rousseau and Saint-Pierre's peace project: a critique of 'history of international relations theory'. In: J AHN, Beate (Org.). Classical theory in international relations. Cambridge: Cambridge University Press, 2006. p. 96-120.

FONSECA J R., G. Prefácio a Rousseau e as relações internacionais. Brasília: Ed. UNB, 2003.

ROUSSEAU, J.-J. The political writings of J ean J acques Rousseau. Introductions and notes C. E. Vaughan. Cambridge: Cambridge University Press, 1915. 2 v. The Online Library of Liberty, 2004.

. Oeuvres complètes. Edited by Bernard Gagnebin and Marcel

Raymond. Paris: Pléiade, 1959-1995. 5 v. 
